\title{
Estudo das Receitas Públicas do Município de Niterói: análise da arrecadação de recursos
}

Estudo das receitas públicas do município de Niterói: análise da arrecadação de recursos

Study of the public revenues of the municipality of Niterói: analysis of the collection of resources

Étude des revenus publics de la commune de Niterói: analyse de la collecte de ressources

Estudio de los ingresos públicos del municipio de Niterói: análisis de la recaudación de fondos.

\section{Mateus Henry de Souza Paes e Rodrigo Portugal}

\section{(2) OpenEdition}

\section{Journals}

Edição electrónica

URL: http://journals.openedition.org/espacoeconomia/8766

DOI: 10.4000/espacoeconomia.8766

ISSN: 2317-7837

Editora

Núcleo de Pesquisa Espaço \& Economia

Refêrencia eletrónica

Mateus Henry de Souza Paes e Rodrigo Portugal, «Estudo das Receitas Públicas do Município de Niterói: análise da arrecadação de recursos », Espaço e Economia [Online], 16 | 2019, posto online no dia 29 dezembro 2019, consultado o 10 janeiro 2020. URL : http://journals.openedition.org/ espacoeconomia/8766; DOI : 10.4000/espacoeconomia.8766

Este documento foi criado de forma automática no dia 10 janeiro 2020.

(C) NUPEE 


\section{Estudo das Receitas Públicas do Município de Niterói: análise da arrecadação de recursos ${ }^{1}$}

Estudo das receitas públicas do município de Niterói: análise da arrecadação de recursos

Study of the public revenues of the municipality of Niterói: analysis of the collection of resources

Étude des revenus publics de la commune de Niterói: analyse de la collecte de ressources

Estudio de los ingresos públicos del municipio de Niterói: análisis de la recaudación de fondos.

Mateus Henry de Souza Paes e Rodrigo Portugal

\section{Introdução}

1 O município de Niterói, localizado na Região Metropolitana do Estado do Rio de Janeiro, apresentou nos últimos anos um elevado crescimento econômico, se comparado a outros municípios brasileiros e até mesmo fluminenses. O Produto Interno Bruto (PIB) praticamente duplicou. De R\$ 12 bilhões em 2010 saltou para R\$ 23 bilhões em 2016, último ano com informações disponíveis.

20 ambiente de pujança econômica e social vivenciado por Niterói se contrapõe às constantes crises fiscais que a federação brasileira e o estado do Rio de Janeiro passaram ao longo das últimas décadas (LESSA, 2000). Assim, é vital abordar as finanças públicas e os setores produtivos a partir das escalas do município, de forma a incorporar distintos aspectos que constituem o orçamento de Niterói, a fim de compreender a procedência das principais receitas para realizar os seus gastos. 
3 Com isso, o estudo analisa como se processou as questões fiscais e financeiras das finanças públicas municipais, a partir das receitas locais e das atividades produtivas. 0 texto mostra a evolução da arrecadação entre 2010-2017 com o intuito de exibir os valores auferidos e analisar as fontes, comparando receita própria, que envolve tributação direta de setores produtivos locais, com transferências correntes, no qual participam rendas repassadas de tributações nacionais ou estaduais.

4 O gráfico abaixo demonstra os primeiros resultados e apresenta a evolução da arrecadação que o município apresentou nos últimos anos, em que quase duplicou sua receita corrente total, graças ao aumento das transferências correntes, que em 2017 alcançaram por volta de $60 \%$ das receitas, enquanto a arrecadação por tributos apresentou uma estabilidade, se descolando das transferências a partir de 2012.

Figura 1 - Receitas Correntes de Niterói (2010-2017). Valores em R\$ milhões, deflacionados para 2017.

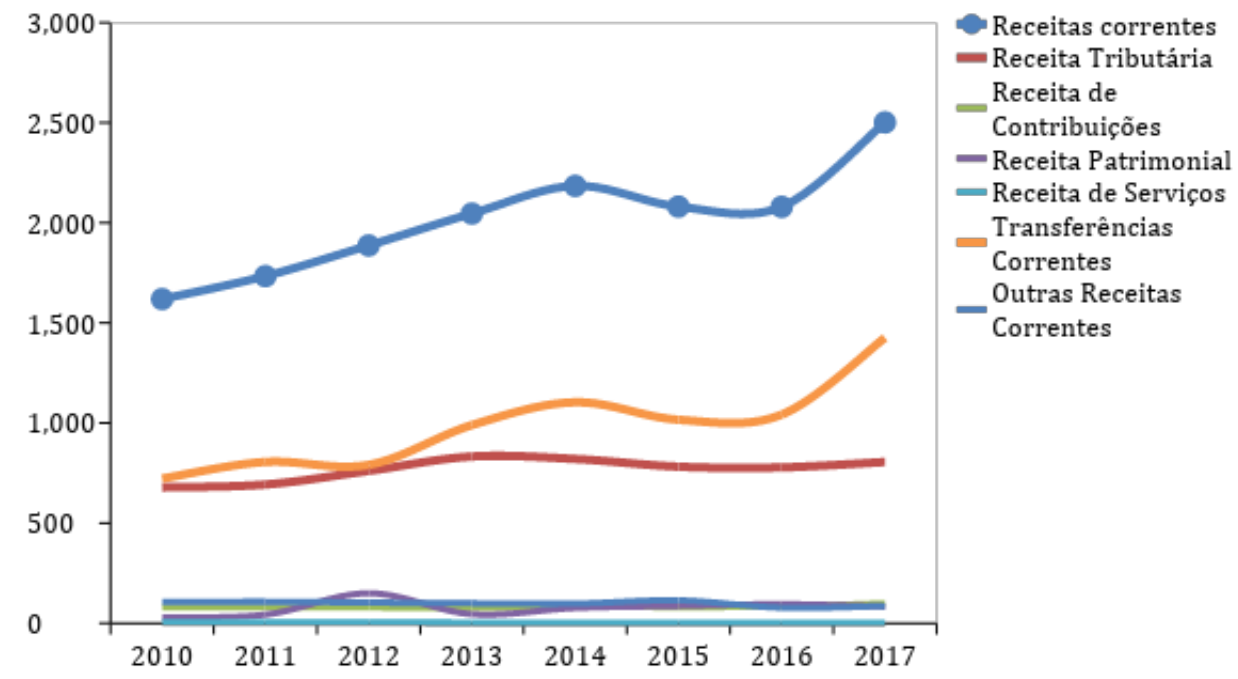

Fonte: Elaboração dos autores com base nos dados do STN (2018)

\section{Destrinchando as receitas e suas fontes}

\section{Transferências Correntes}

5 A maior parcela de receitas correntes de Niterói foi oriunda das transferências correntes, recursos transferidos entre pessoas de direito público ou privado para realizar gastos correntes, que podem ser de diversas maneiras, entre eles os royalties, compensações financeiras pela exploração de um recurso não renovável, e as Participações Especiais, compensações em caso de grande volume de produção, no qual a soma de ambos é denominada de participações governamentais (MPRJ, 2018; ANP 2018).

6 Mais recentemente, a chamada economia do petróleo tornou-se um dos pilares de sustentação do crescimento econômico e das finanças do Estado do Rio de Janeiro, com destaque para o papel que as compensações financeiras têm exercido nos cofres estaduais e dos municípios de alguma forma impactados pelo setor (SILVA, 2017). 
7 A exploração petrolífera na costa fluminense e niteroiense deu direito ao município de cota-partes das participações governamentais, que se expandiram na última década com o início das operações da camada pré-sal, e em particular do campo de Lula, que possui $43 \%$ de confrontação continental com Niterói (ANP, 2018, p. 10). Segundo dados do Ministério Público estadual (MPRJ, 2018, p. 12) a produção de Lula passou de 86 mil barris/dia em 2013 para 879 barris/dia em 2017, propiciando maior volume de participações transferidas para Niterói, que são calculadas em função do preço e da quantidade explorada.

8 Historicamente, a exploração da camada pós-sal, iniciada desde 1978, proporcionou preferencialmente participações governamentais para os municípios confrontantes com a Bacia de Campos situados no norte fluminense, como Campos dos Goytacazes e Macaé, principalmente (PIQUET et al, 2011). Porém, com o início da exploração do présal, transferiu-se parte desses recursos para os municípios da Bacia de Santos, principalmente em São Paulo, e estado do Rio de Janeiro, como Niterói e Maricá, que não haviam usufruído das transferências relativas à exploração do pós-sal.

9 Assim, as participações governamentais derivadas da extração de petróleo no território nacional originaram 05 tipos de transferências para Niterói: i) a compensação financeira pela exploração dos recursos naturais (Lei $\left.\mathrm{n}^{\circ} 7.990 / 89\right)$ - royalties em si; ii) cota-parte pelo excedente da produção (Lei $n^{\circ}$ 9.478/97 artigo 49 I e II) - quando a parcela dos royalties exceder 5\% da produção; iii) Participação Especial (Lei nº 9.478/97 artigo 50); iv) cota-parte do Fundo Especial do Petróleo - fundo repartido com alguns entes federativos, não só produtores; e v) royalties transferidos pelo estado do Rio de Janeiro (art. 9º da Lei no ${ }^{\circ}$ 7.990/1989) .

10 Entre eles, quem se destacou foram as Participações Especiais, e consequentemente o campo de Lula, nas transferências correntes ao município. Em 2017, Niterói foi o segundo município que mais arrecadou com transferências petrolíferas, atrás somente de Maricá. Conforme a figura a seguir, de 2010 a 2017, os recursos destinados a Niterói com participações especiais saltaram de zero para $\mathrm{R} \$ 343$ milhões, acompanhado das transferências pelo excedente de produção. O Fundo de Participação do Petróleo nunca foi significativo, assim como as transferências de royalties pelo estado do Rio de Janeiro, enquanto os royalties tradicionais federais apresentaram declínio. Para verificar a magnitude do campo de Lula, no quarto trimestre de 2017 foi arrecadado nele $R \$ 3,3$ bilhões somente em participações especiais, destinados a vários entes federativos, entre eles Niterói, Maricá e o estado do Rio de Janeiro, valor muito superior aos $\mathrm{R} \$ 400$ milhões de Sapinhoá, o segundo colocado (ANP, 2018, p. 9).

11 Em comparação a outros instrumentos de transferência como o Fundo de Participação dos Municípios (FPM), uma das principais fontes de recursos dos municípios brasileiros, Niterói recebeu em 2017 R \$ 59 milhões, valor inferior aos R 348 milhões da parcela de participações especiais destinados a ele. 
Figura 2 - Royalties do petróleo (2010-2017) - Valores em R\$ milhões, deflacionados para 2017.
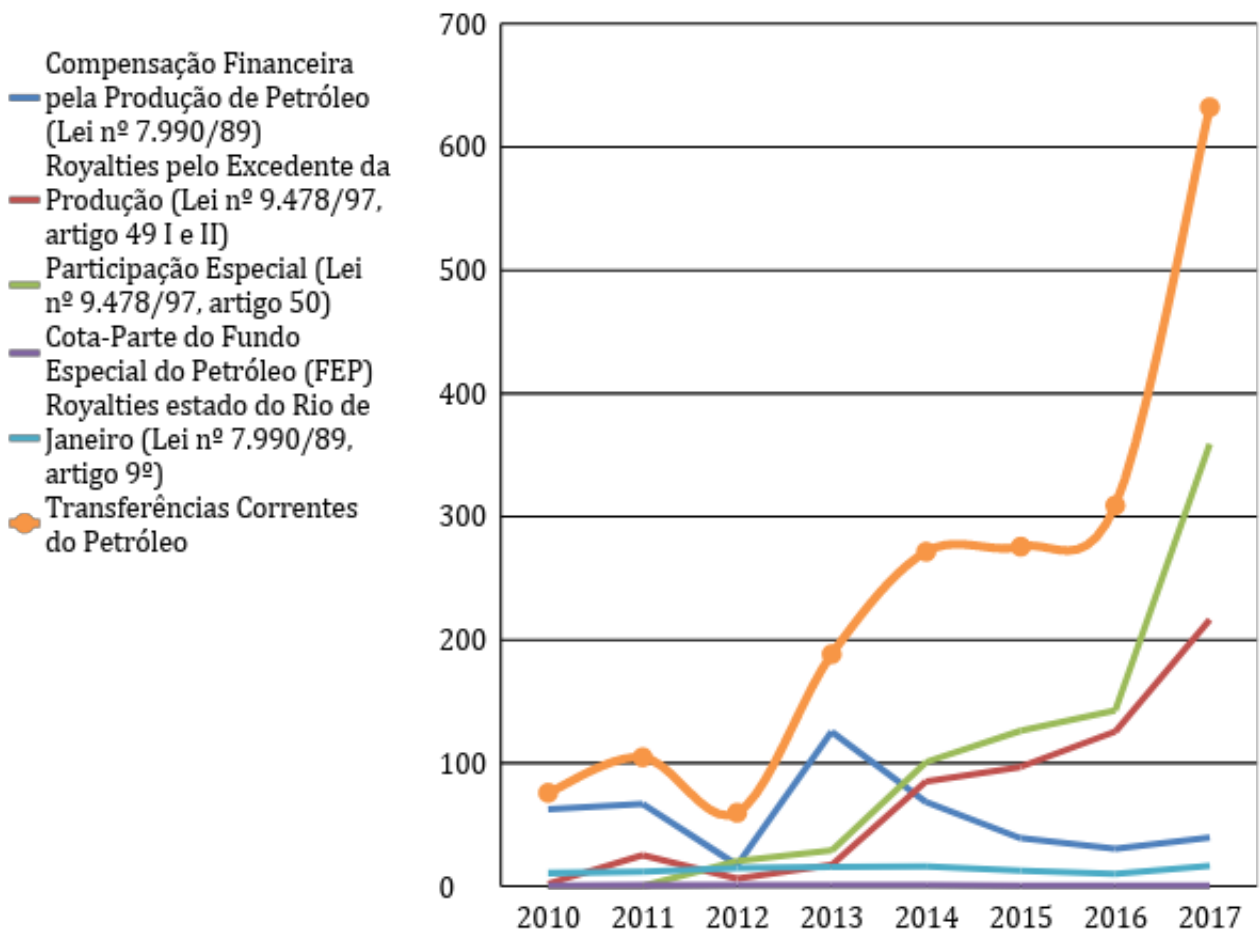

FONTE: Elaboração dos autores com base nos dados do STN (2018)

\section{Receita Patrimonial}

12 A elevação das transferências pode ocasionar aumento das receitas patrimoniais, que corresponde, entre outros ${ }^{2}$, aos recursos obtidos através dos bens mobiliários (remuneração de depósitos bancários). Assim, quanto mais recursos transferidos, mais remunerações bancárias propiciadas. Apesar de ser uma pequena parcela da receita corrente total - gira em torno de 3\% - apresenta resultados importantes.

De acordo com os relatórios de gestão de Niterói (2017a), os valores mobiliários são os maiores componentes da receita patrimonial nos anos analisados, ressaltando o aspecto financeiro das finanças públicas municipais. o petróleo reverbera não somente no setor produtivo, mas também na remuneração dos depósitos de transferências correntes.

Em 2017, as remunerações corresponderam a R \$ 56 milhões, superando a arrecadação de tributos como as taxas ( $\mathrm{R} \$ 48$ milhões) e chegando próximo aos níveis do Imposto sobre transmissão intervivos de bens imóveis - ITBI (R\$ 61 milhões) e das transferências do Fundo de Participação dos Municípios - FPM (R\$ 59 milhões). A maior parcela remeteu à remuneração de depósitos bancários ( $\mathrm{R} \$ 2$ milhões) ${ }^{3}$ dos recursos transferidos vinculados, como a seguridade social (Regime Próprio de Previdência Social - RPPS), a saúde (Fundo Nacional de Saúde - FNS) e a manutenção e desenvolvimento do ensino, ações e serviços públicos de saúde (ASPS). Este último, aliás, foi o responsável pelo salto do componente das receitas patrimoniais de 2011 para 2012.

Os royalties do Petróleo normalmente não são vinculados a nenhum tipo de gasto, porém em 2017 uma única remuneração de depósito (4.1.3.2.5.01.99.51.00.00) 
correspondeu a R $\$ 25$ milhões (NITERÓI, 2017a, p. 2), valor muito superior aos R 2 mil orçados e quase metade das remunerações bancárias. $O$ artigo $7^{\circ}$, $\S 2$ da lei $n^{\circ}$ 7.990/1989 (BRASIL, 1989) não veda o uso de compensações financeiras, como as participações governamentais, para capitalização de fundos previdenciários, sendo assim, R\$ 100 milhões em transferências foram aportadas para o RPPS (NITERÓI, 2018b), deficitário orçamentariamente, o que tornou os rendimentos vinculados e computados como receitas patrimoniais.

\section{Receita Tributária}

16 A receita tributária corresponde a arrecadação por meio de tributos (impostos e taxas) ${ }^{4}$ e se configurou no segundo maior componente das receitas correntes. É a partir dele que o município tributa diretamente o patrimônio (Imposto Predial e Territorial Urbano - IPTU e ITBI), a renda (o imposto de renda, tributo federal, pago pelos servidores municipais fica como arrecadação para o município de origem) e parte da atividade econômica (Imposto sobre serviços de qualquer natureza - ISS), além de taxar a sociedade quando exerce o seu poder de polícia (vigilância sanitária, licença para comércio ambulante, licença ambiental e licença para execução de obras) e quando presta um serviço (taxa de limpeza pública).

17 A arrecadação tributária diminuiu entre 2010 e 2017 de $42 \%$ para $32 \%$ da receita corrente total e apresentou algumas peculiaridades. O ISS variou negativamente a partir de 2014, ano de início da desaceleração econômica brasileira, pois tributa setores sensíveis à conjuntura, como a construção civil e atividades administrativas, principais atividades arrecadadoras do tributo. 0 gráfico abaixo mostra a situação de descenso de ambas em termos de salários ${ }^{5}$ e a queda em ritmo similar da arrecadação sobre a produção e a circulação.

Figura 3 - Tributação sobre o patrimônio e a renda, sobre a produção e a circulação e o setor de construção e atividades administrativas - Valores em R\$ milhões, deflacionados para 2017.

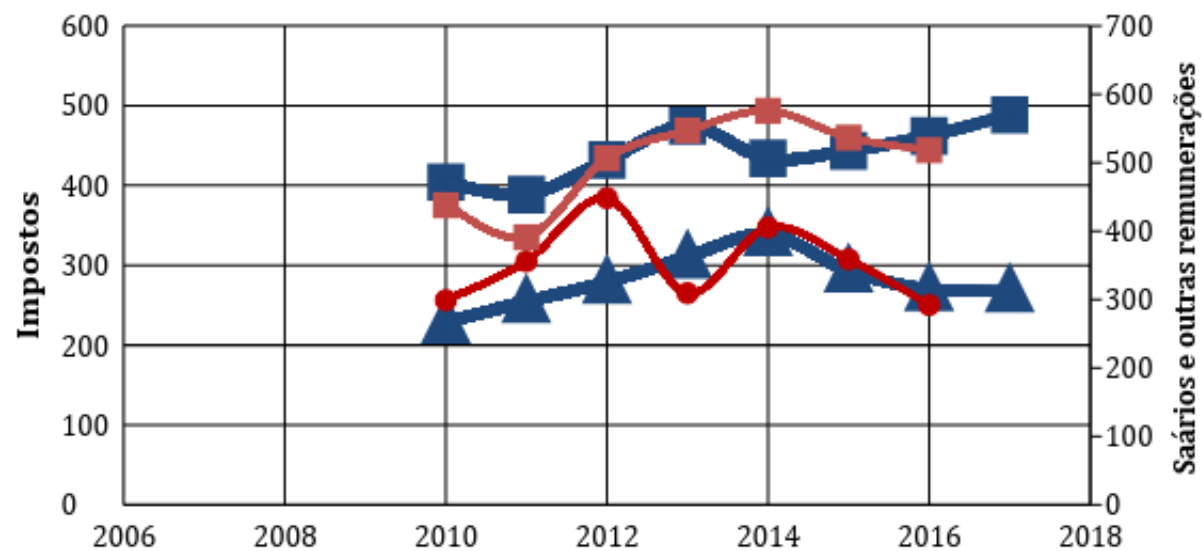

Patrimônio e renda

Produção e circulação

F Construção

N Atividades administrativas e serviços complementares

Fonte: Elaboração dos autores com base em IBGE (2018a) e Niterói (2017). 
Por outro lado, o gráfico apresenta uma elevação das receitas sobre o patrimônio e a renda, pois como explica Carvalho Junior (2018, p. 413) a tributação patrimonial (IPTU) é pouco afetada pela conjuntura econômica, uma vez que os valores venais dos imóveis estão quase sempre abaixo do valor de mercado. Tal fator contribui para estabilidade da arrecadação patrimonial ou mesmo o aumento sem relação com a economia, como a atualização cadastral realizada em Niterói em 2016 (ROSA, 2015).

Vale ressaltar também a retração da economia ligada ao petróleo, que não é tributada diretamente pelo ISS, mas possui importância na economia local. De acordo com o IBGE (2018b), a indústria do petróleo ocupou a segunda colocação em valor adicionado ao Produto Interno Bruto (PIB) de Niterói em 2013 e 2014, ao passo que nem figurou entre as três primeiras em 2016. Essa retração também pode ser verificada em relação ao número de empresas, em 2013 o setor chegou a ter 16 empresas na cidade, enquanto em 2016 só possuía 09 (IBGE, 2018a), o que ressalta a ainda incipiente participação de empresas em terra (on shore) nas atividades ligadas ao petróleo em Niterói.

O crescimento da arrecadação correspondeu mais a compensações financeiras do que produção efetiva. A cadeia produtiva, no caso do petróleo, seria a de empresas on shore ligadas à exploração, produção, atividades dos estaleiros e de empresas prestadoras de serviço à produção.

21 No caso dos municípios ligados à indústria petrolífera em mar territorial (off shore), como Niterói, o valor da produção correspondente à área confrontante é computado ao PIB, mas o município só recebe as transferências financeiras; a base física, em terra, das empresas que realizam a exploração e produção do petróleo não está no município, em geral, o que não contribui para uma elevação substancial na arrecadação de ISS e IPTU.

Conforme consta em IBGE (2018a), no Norte Fluminense, 05 municípios recebem elevadas transferências das rendas petrolíferas, mas só Macaé possui as instalações físicas das empresas ligadas diretamente à exploração e produção. Nesse caso, apesar do PIB conter o valor da produção e o município ser classificado como produtor, ele não possui as empresas que realizam a produção, se configurando em uma atividade que proporciona rendas, mas não necessariamente gera efeitos produtivos no local (IBGE, 2018b).

\section{Receitas de contribuições sociais, serviços e outras receitas correntes.}

23 As receitas de contribuições sociais são espécies de tributos vinculados para financiar a seguridade social. Niterói (2017a) mostra que boa parte da arrecadação é oriunda dos servidores ativos para financiar o RPPS, que assegura, no mínimo, os benefícios de aposentadoria e pensão por morte dos seus segurados e seus beneficiários. No entanto, assim como em outros municípios, o RPPS de Niterói encontra-se em déficit orçamentário e o governo municipal faz aportes para equalizá-lo. Em 2017, foi feito um aporte de R\$ 100 milhões (NITERÓI, 2018b), oriundo das transferências correntes, a maior oscilação de execução orçamentária, o que beneficiou o rendimento financeiro como visto acima (ver figura 2). 
Figura 4 - Análise da contribuição para seguridade social do município de Niterói (2010-2017) Valores em R\$ milhões, deflacionados para 2017.
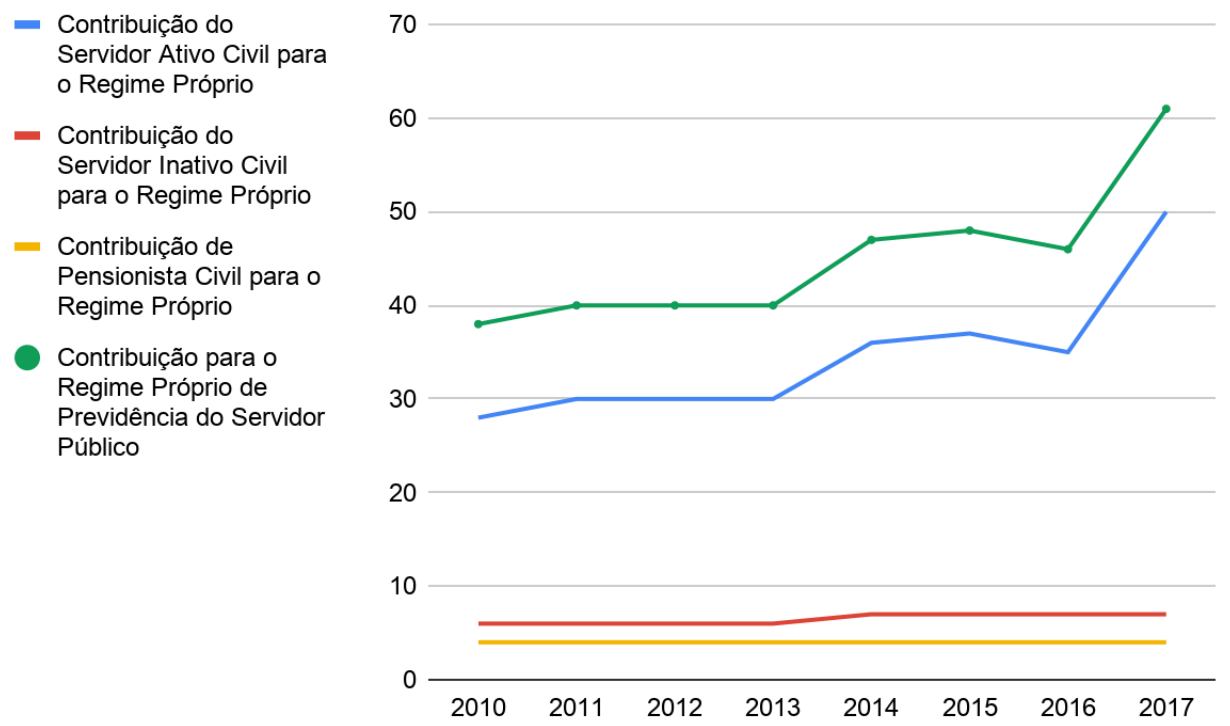

FONTE: Elaboração dos autores com base nos dados do STN (2018) e Niterói (2017).

A receita de serviços, proveniente de prestações públicas do governo municipal à população não chegou a $0,3 \%$ da receita corrente, o que demonstra a baixa arrecadação do ente federativo quando oferece serviços financeiros, de cemitério ou de tratamento de resíduos. As outras receitas correntes também apresentaram baixa participação, apesar de conterem receitas com multas e juros de mora, indenizações e restituições e da cobrança de dívida ativa.

\section{Receitas de capital}

Figura 5 - Receitas de Capital de Niterói (2010-2017). Valores em R\$ milhões, deflacionados para 2017.
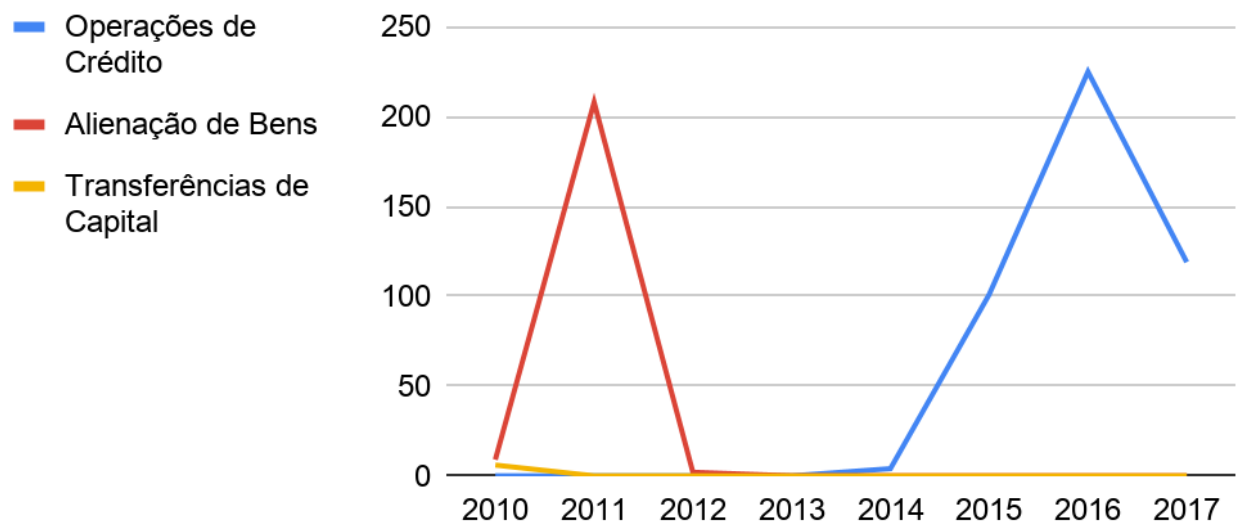

FONTE: Elaboração dos autores com base nos dados do STN (2018) 
As receitas de capital são originárias das constituições de dívidas, além do auferimento de recursos financeiros sobre bens e direitos, ou seja, investimentos feitos pela administração pública para manutenção de seu funcionamento.

26 De acordo com Niterói (2017a), a notável evolução das Receitas de Capital a partir de 2015 justificam-se por um empréstimo realizado pelo município de Niterói junto ao CAF (Cooperação Andina de Fomento) objetivando a realização de obras na infraestrutura da Região Oceânica de Niterói, que faz parte do projeto de revitalização e urbanização municipal. Em 2016, quando houve a efetivação do empréstimo, houve a construção da orla de Niterói, proporcionando uma vista privilegiada do município vizinho, local onde ocorriam os Jogos Olímpicos. No ano de 2017 o município utilizou o recurso auferido para dar continuidade ao seu projeto de infraestrutura, com obras na TransOceânica (Túnel Charitas-Cafubá) e revitalizações no Centro e Zona Sul da cidade.

27 No período entre 2010 e 2012, o município fez um aporte de $\mathrm{R} \$ 205$ milhões com a alienação de bens móveis, entre títulos e mercadorias, além da alienação de propriedades do município (NITERÓI, 2018b). De acordo com dados de Niterói (2017a), as transferências de capital foram provenientes de convênio do município com a União, almejando melhorias no SUS, com a finalidade de satisfazer as finalidades públicas de saúde.

\section{Receitas correntes intra-orçamentárias}

28 A classificação de receita corrente intra-orçamentária foi definida mais de 40 anos depois da lei de 1964, através da Portaria Interministerial STN/SOF nº 338, de 26 de abril de 2006, que conceitua que são receitas de instituições governamentais decorrentes de despesas de outras instituições presentes no mesmo orçamento, ou seja, são receitas oriundas de instituições constantes em um mesmo âmbito governamental, neste caso, municipal, atuante na composição do orçamento fiscal e, principalmente, na seguridade social, objetivando auxiliar a execução da LRF (Lei de Responsabilidade Fiscal).

29 De acordo com Garson (2018, p. 144), a distinção de nomenclatura das receitas correntes intra-orçamentárias para as demais possui relevância para a correta elaboração do orçamento de determinada esfera governamental por ter relações diretas entre órgãos, fundos e entidades provenientes de uma mesma esfera, contribuindo para que não haja uma dupla contagem nos balanços governamentais em relação às receitas ou despesas, identificando, assim, os tipos de lançamentos nos instrumentos orçamentários (PPA, LDO, LOA).

30 Portanto, nota-se no gráfico abaixo que a composição das receitas do município de Niterói possui foco na manutenção da máquina pública, isto é, visa o equilíbrio financeiro e fiscal, em contrapartida do investimento governamental, com as receitas de capital priorizando projetos de urbanismo. Por fim, com as receitas correntes intraorçamentárias, percebemos que há uma tendência do município de alavancar recursos para a seguridade social (RPPS), no qual os gastos financiam as entidades locais, mas retornam aos cofres em forma de receita, porém, a baixa captação do setor, visto em outros municípios brasileiros, faz com que tenha uma dependência de aportes governamentais a fim de garantir a sua sustentabilidade e desenvolvimento. 
Figura 6 - Receitas públicas do município de Niterói (2010-2017). Valores em R\$ milhões, deflacionados para 2017.
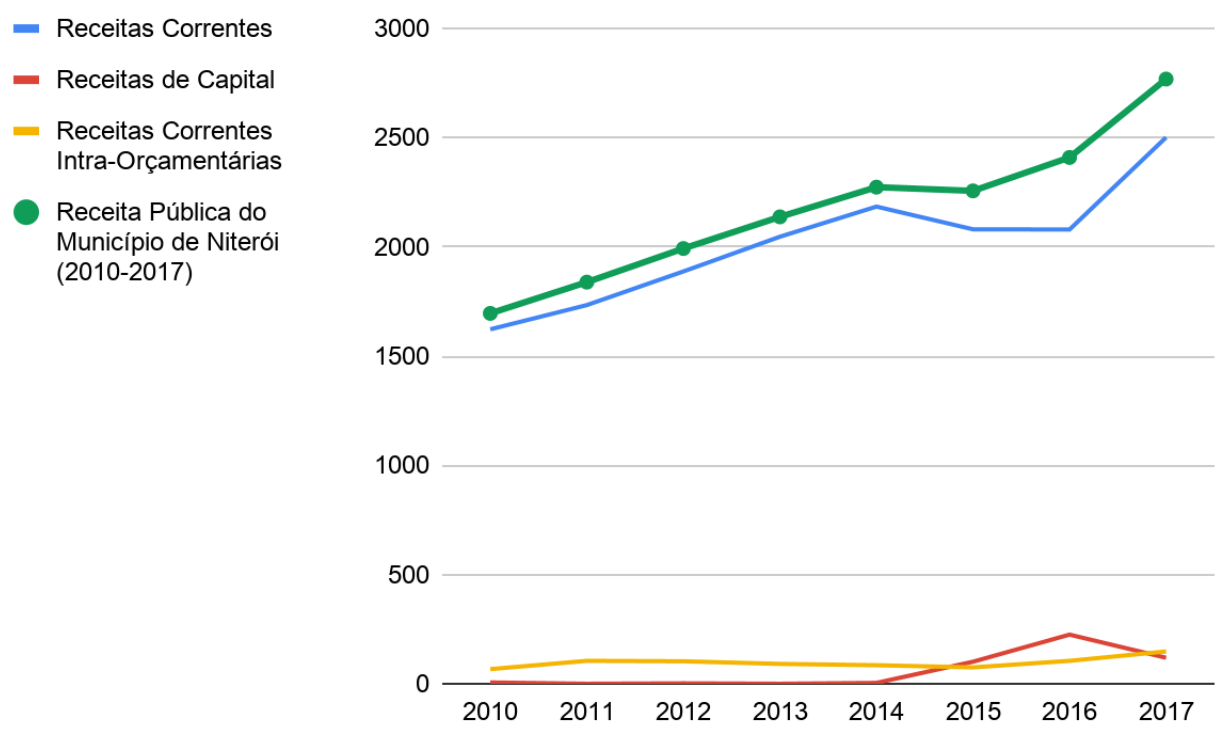

FONTE: Elaboração dos autores com base nos dados do STN (2018)

\section{Conclusão:}

31 A análise buscou relacionar os setores componentes das receitas públicas de forma unificada e identificar a importância das atividades produtivas nas receitas municipais. Destaca-se o setor petrolífero pelas participações governamentais transferidas ao Tesouro de Niterói, possibilitadas pelo aumento da produção da camada pré-sal no campo de Lula, e pelos desdobramentos nos outros componentes de receita, como a tributária, a patrimonial e de contribuições sociais. $O$ aumento das transferências elevou a receita patrimonial a partir das remunerações dos depósitos bancários, assim como possibilitou aportes para capitalização do fundo previdenciário municipal.

Conclui-se que a atividade petroleira é o principal fator de elevação das receitas tributárias em Niterói, mas ressalta-se a queda em setores econômicos, como de construção e atividades administrativas, grandes arrecadadores de ISS, e do próprio setor de petróleo, que apesar de proporcionar grandes transferências, gerou menor valor adicionado ao PIB do município desde 2014. Portanto, em termos de arrecadação proveniente da atividade produtiva, o petróleo não se mostrou expressivo, por ainda ter uma incipiente capacidade implantada on shore, ao contrário do verificado quanto às transferências correspondentes às rendas (royalties e participações especiais), o que denota um perfil de arrecadação com maior peso nas transferências correntes do que nas atividades produtivas do petróleo.

33 Além disso, nota-se como o município beneficiou-se dos recursos provenientes de instituições arrecadatórias locais, mais especificamente àquelas que tributam sobre a seguridade social, vistos nas receitas intra-orçamentárias, obtendo participação de $36 \%$ sobre as receitas totais, 9 pontos percentuais acima das receitas de capital, oriundas de créditos externos (NITERÓI, 2017a), utilizados no financiamento de obras públicas para melhorias na infraestrutura e em movimentações financeiras com esta finalidade. 
o assim, o setor petrolífero constituiu o principal agente para ascensão econômica de Niterói, propiciando elevação das transferências constitucionais por participações governamentais, e uma retração da atividade econômica no município a partir de 2014, o que prejudicou a arrecadação direta por meio do imposto sobre serviços (ISS), além de inferir na tributação sobre patrimônio e renda.

\section{BIBLIOGRAFIA}

AGÊNCIA NACIONAL DO PETRÓLEO, GÁS NATURAL E BIOCOMBUSTÍVEIS (ANP). Relatório Trimestral de Participação Especial (PE): 1ำ Trimestre de 2018 (1T/18). Rio de Janeiro: ANP, 2018. Disponível em: <https://bit.ly/2VgedK5>. Acesso em: 18 mar. 2019.

AMARO, Luciano. Direito Tributário Brasileiro. 12. ed. São Paulo: Saraiva, 2006.

BRASIL. Lei no 7.990 , de 28 de dezembro de 1989. Institui, para os Estados, Distrito Federal e Municípios, compensação financeira pelo resultado da exploração de petróleo ou gás natural, de recursos hídricos para fins de geração de energia elétrica, de recursos minerais em seus respectivos territórios, plataformas continentais, mar territorial ou zona econômica exclusiva, e dá outras providências. (Art. 21, XIX da CF). Diário Oficial [da] República Federativa do Brasil, Brasília, 29. dez. 1989. Disponível em: <https://bit.ly/2tDMkQk>. Acesso em: 20 fev. 2019.

BRASIL. Portaria Interministerial no 338, de 26 de abril de 2006. Altera o Anexo I da Portaria Interministerial STN/SOF no 163, de 4 de maio de 2001, e dá outras providências. Diário Oficial [da] República Federativa do Brasil, Brasília, DF, 28 abr. 2006. Disponível em: <http:// www.orcamentofederal.gov.br/Ptr_Intermin_338_de_260406.pdf>. Acesso em: 22 mar. 2019.

CARVALHO JÚNIOR, Pedro Humberto Bruno de. Imposto Predial e Territorial Urbano (IPTU). In: FAGNANI, Eduardo (org.). A Reforma Tributária Necessária: diagnóstico e premissas. Brasília: ANFIP, 2018.

GARSON, Sol. Planejamento, orçamento e gasto com políticas públicas: uma metodologia de apuração para Estados e Municípios. Porto Alegre, RS: Editora Fi, 2018. Disponível em: <https:// www.editorafi.org/315solgarson>. Acesso em: 22 mar. 2019.

INSTITUTO BRASILEIRO DE GEOGRAFIA E ESTATÍSTICAS (IBGE). Cadastro Central de Empresas: Tabela 6450 - Variável Salários e outras remunerações (Mil Reais). Rio de Janeiro: IBGEa, 2018. Disponivel em: <https://bit.ly/2H03L5E>. Acesso em: 18 mar. 2019.

Produto Interno bruto dos municípios: Tabela 5938. Rio de Janeiro: IBGE, 2018b.

Disponível em: <https://bit.ly/2Td2Zc9>. Acesso em: 18 mar. 2019.

LESSA, Carlos. 0 Rio de todos os Brasis: uma reflexão em busca de auto-estima. Rio de Janeiro: Record, 2000. p. 346.

MINISTÉRIO PÚBLICO DO ESTADO DO RIO DE JANEIRO (MPRJ). Análise da evolução das receitas das participações governamentais petrolíferas para os municípios que compõem o núcleo Niterói de tutela coletiva: Maricá e Niterói. Laboratório de análises de orçamentos e de políticas públicas. (LOPP/MPRJ), 2018. Disponível em: <https://bit.ly/2BT1qGu>. Acesso em: 19 mar. 2019. 
NITERÓI. Prefeitura municipal. Anexo 10 - Comparativo da receita orçada arrecadada. Niterói: Prefeitura municipal, 2017a. Disponível em: <https://bit.ly/2qWTUDP>. Acesso em: 20 mar. 2019.

Relatório resumido da execução orçamentária (RREO) - Anexo 4: Demonstrativo das Receitas e Despesas Previdenciárias do Regime Próprio dos Servidores Públicos 6 bimestre. Niterói: Prefeitura municipal, 2017b. Disponível em: <https://bit.ly/2qWTUDP>. Acesso em: 20 mar. 2019.

PIQUET, Rosélia; SERRA, Rodrigo; TERRA, Denise; CRUZ, José Luiz Vianna da; ROCHA, Aristotelina; NAZARETH, Paula. A Indústria do Petróleo e a Exploração do Pré-Sal: seu papel no processo de desenvolvimento regional e nacional. In: Encontro Nacional da ANPUR. 14. 2011, Rio de Janeiro. Anais... Rio de Janeiro: ANPUR UFRJ UFF, 2011, v. 1, p. 1-2.

ROSA, Gabriel. Prefeitura de Niterói recalcula alíquota de IPTU de cerca de dez mil imóveis. 0 Globo. Rio de Janeiro, 27 dez 2015. Disponível em: <https://glo.bo/2SZDKdR>. Acesso em: 19 fev. 2019.

SECRETARIA DO TESOURO NACIONAL (STN). FINBRA. Finanças do Brasil - Dados Contábeis dos Municípios. Brasília: STN, 2018a. Disponível em: <https://bit.ly/2Qe18hW>. Acesso em: 10 mar. 2018.

SILVA, Robson Dias da. Royalties e Desenvolvimento Regional: uma reflexão sobre os desafios do rio de janeiro. In: Desenvolvimento Regional no Brasil - Políticas, estratégias e perspectivas. MONTEIRO NETO, A; CASTRO, C. N; BRANDÃO, C. A. Brasília: IPEA, 2017.

\section{NOTAS}

1. Os autores agradecem aos pareceristas da Revista Espaço e Economia pelas contribuições essenciais e relevantes ao texto, assim como a prof ${ }^{a}$ Hipólita Siqueira do IPPUR/UFRJ pela oportunidade de iniciar a pesquisa.

2. São incluídas também receitas de bens imobiliários (aluguéis) e da concessão ou permissão ao particular do direito de exploração de serviços públicos.

3. Todos os dados em valores correntes de 2017, extraídos de Niterói (2017a).

4. No orçamento de Niterói optou-se por separar receita tributária (impostos e taxas) das receitas de contribuições sociais, porém autores como Amaro (2006, p. 52) consideram ambos, espécies de tributos.

5. Os dados foram extraídos de IBGE (2018b) a partir do setor de construção (F) e Atividades administrativas e serviços complementares $(\mathrm{N})$ conforme a Classificação Nacional de Atividades Econômicas (CNAE).

\section{RESUMOS}

O artigo analisa as receitas públicas do município de Niterói no período de 2010-2017, de modo a compreender a base econômica municipal, destacando os setores produtivos na arrecadação e relacionando seus desdobramentos nos componentes da receita corrente, como a receita tributária, patrimonial, de transferências, de serviços e de contribuições sociais, da receita de 
capital, como as operações de crédito, alienação de bens e transferências de capital, além de demonstrar a aplicação da receita intra-orçamentária no orçamento governamental e referente impacto na economia local.

Portanto, será feita uma análise de 2010-2017 sobre a composição da receita municipal de Niterói disponibilizada pela Secretaria de Planejamento, Modernização da Gestão e Controle (SEPLAG) e da execução orçamentária do referido município, disponibilizada pela Secretaria do Tesouro Nacional (STN) do Governo Federal.

The article analyzes the public revenues of the municipality of Niterói in the period 2010-2017, in order to understand the municipal economic base, highlighting the productive sectors in the collection and relating their unfolding in the components of current revenue, such as tax revenue, assets, transfers and social contributions, capital income, such as credit operations, sale of assets and capital transfers, as well as demonstrating the application of intra budgetary revenue in the government budget and impact on the local economy.

Therefore, a 2010-2017 analysis will be done on the composition of the Niterói municipal revenue provided by the Secretariat for Planning, Modernization of Management and Control (SEPLAG) and the budgetary execution of said municipality, made available by the National Treasury Secretariat (STN) of Federal government.

L'article analyse les revenus publics de la commune de Niterói sur la période 2010-2017 afin de comprendre la base économique municipale, en mettant en évidence les secteurs productifs de la collecte et en relatant leur évolution dans les composantes des recettes courantes, telles que les recettes fiscales, les actifs, transferts, services et cotisations sociales, revenus du capital, tels que les opérations de crédit, la vente d'actifs et les transferts de capitaux, ainsi que la démonstration de l'application des revenus intra budgétaires dans le budget de l'État et son impact sur l'économie locale.

Par conséquent, une analyse 2010-2017 sera réalisée sur la composition des recettes municipales de Niterói fournies par le Secrétariat pour la planification, la modernisation de la gestion et le contrôle (SEPLAG) et l'exécution budgétaire de ladite municipalité, mise à disposition par le Secrétariat du Trésor national Gouvernement fédéral.

El artículo analiza los ingresos públicos del municipio de Niterói en el período 2010-2017, con el fin de comprender la base económica municipal, destacando los sectores productivos en la recaudación y relacionando su evolución en los componentes de los ingresos corrientes, como los ingresos fiscales y patrimoniales. transferencias, servicios y contribuciones sociales, ingresos de capital, tales como operaciones de crédito, disposición de activos y transferencias de capital, así como demostrar la aplicación de ingresos intrapresupuestarios al presupuesto gubernamental y su impacto en la economía local.

Por lo tanto, se realizará un análisis 2010-2017 de la composición de los ingresos municipales de Niterói puestos a disposición por la Secretaría de Planificación, Modernización de la Gestión y Control (SEPLAG) y la ejecución del presupuesto de ese municipio, puesto a disposición por la Secretaría del Tesoro Nacional (STN). Gobierno federal.

\section{ÍNDICE}

Mots-clés: Niterói; budget municipal; transfert de royalties; les revenus.

Keywords: Niterói; municipal budget; royalty transfer; ; public revenues.

Palabras claves: Niterói; presupuesto municipal; transferencias de royalties; ingresos públicos

Palavras-chave: Niterói; orçamento municipal; transferências de royalties; receitas públicas. 


\section{AUTORES}

\section{MATEUS HENRY DE SOUZA PAES}

Graduando em Gestão Pública GPDES/UFRJ

Universidade Federal do Rio de Janeiro

e-mail: mateus.henry07@gmail.com

(21) 97917-6399

Endereço: Av. Pedro Calmon, 550 - Cidade Universitária, Rio de Janeiro - RJ

\section{RODRIGO PORTUGAL}

Professor GPDES/UFRJ. Economista da Superintendência do Desenvolvimento da Amazônia (Sudam). Doutorando em Planejamento Urbano e Regional (IPPUR/UFRJ)

Universidade Federal do Rio de Janeiro

e-mail: rodrigo.portugal88@gmail.com

(91) 98011-9006

Endereço: Av. Pedro Calmon, 550 - Cidade Universitária, Rio de Janeiro - RJ 